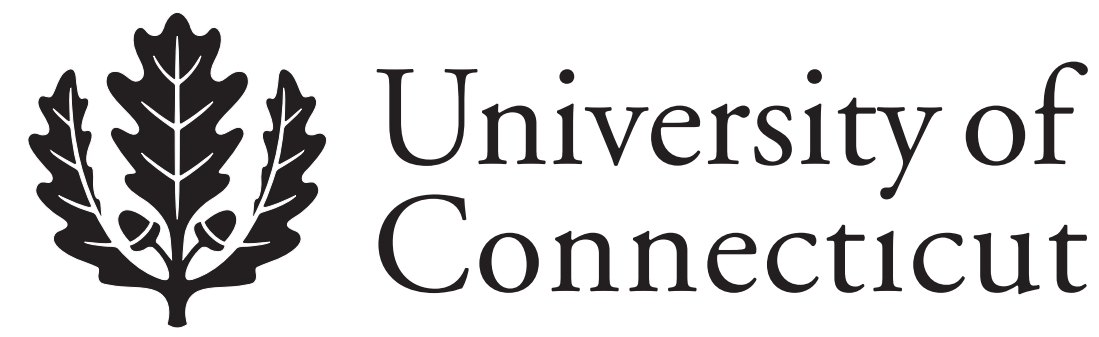

Department of Economics Working Paper Series

Holdups and Holdouts: What do They Have in Common?

Thomas J. Miceli

University of Connecticut

Kathleen Segerson

University of Connecticut

Working Paper 2011-06

April 2011

341 Mansfield Road, Unit 1063

Storrs, CT 06269-1063

Phone: (860) 486-3022

Fax: (860) 486-4463

http://www.econ.uconn.edu/

This working paper is indexed on RePEc, http://repec.org/ 


\begin{abstract}
The holdup and holdout problems arise in different contexts, but they share certain fundamental similarities that have not generally been recognized. In particular, both involve activities requiring an up-front, non-salvageable investment, and both require the investor to purchase an input, the price of which is determined by bargaining after the initial investment has been made. The effect of the up-front investment is to reduce the investor's bargaining power with the seller of the input. The anticipation of the outcome of this bargaining creates a disincentive for the investor to undertake the project in the first place, causing some efficient projects to be foregone.
\end{abstract}

Journal of Economic Literature Classification: D23, K11, L14, L23

Keywords: Holdup problem, holdout problem, non-salvageable investments, eminent domain 


\section{Holdups and Holdouts: What do They Have in Common?}

\section{Introduction}

The "holdup" problem and the "holdout" problem are familiar phrases to economists. The similarity of the names may lead some to believe they describe the same problem and can be used interchangeably, but in fact, the two terms have been used to describe problems that arise in quite distinct contexts. The holdup problem usually arises in a contracting situation in which one or both of the parties makes transaction-specific investments prior to trade that enhance the value of trade. However, because the parties cannot sign completely enforceable contingent contracts before making their investments, they fear losing a portion of the return on those investments in subsequent bargaining. As a result, they tend to under-invest. Much of the literature on the holdup problem thus discusses organizational responses like vertical integration or long term contracts as ways of improving investment incentives. ${ }^{1}$

The holdout problem, in contrast, typically describes a situation in which a developer seeks to assemble a large number of contiguous, separately owned properties for purposes of undertaking a large scale project like a highway or shopping center. ${ }^{2}$ Economists and legal scholars have long recognized the role of the holdout problem in impeding the efficient assembly of land, but in contrast to the holdup problem, there does not seem to be a consensus on the real source of the problem. For example, it has variously been described as a problem of transaction costs (Cooter, 2000, p. 289), monopoly (Posner, 2003, p. 55), asymmetric information (Strange, 1995), rent seeking (Goldberg, 1985), and anti-commons (Heller, 1999, p. 1170). There is

\footnotetext{
${ }^{1}$ The large literature on the holdup problem includes Williamson (1975, 1985), Goldberg (1976, 1985), Klein, Crawford, and Alchian (1978), Hart and Moore (1988), Edlin and Reichelstein (1996), and Segal (1999). Also see the survey in Bolton and Dewatripont (2005, pp. 560-578).

${ }^{2}$ The problem is not limited to assembly of land, however (Menezes and Pitchford, 2004). For example, an entrepreneur may need to acquire several patents in order to market a product.
} 
agreement, however, that a forced sale (for example, eminent domain) may be necessary to overcome the problem (Miceli and Segerson, 2007).

The purpose of this paper is to argue that, despite the apparently different contexts in which these problems arise, they are actually two manifestations of the same underlying economic problem. Specifically, we will argue that both arise from the need (or desire) of one party to a potential transaction to make specific investments prior to trade that lock him into the transaction. This in turn confers bargaining power on another party or parties, who are therefore able to extract quasi-rents from the transaction in a way that affects the (marginal) returns to investment. In anticipation of this, the first party will be reluctant to make the initial investments, resulting in a loss of some potential gains from trade.

As a way to motivate the formal analysis of this proposition, the next section provides some illustrations of the holdup and holdout problems from the case law. Sections 3 and 4 then develop simple models of the two problems in order to illustrate their commonality. Whereas the model of the holdup problem in Section 3 is a standard one from the literature, the model of the holdout problem in Section 4 is, to our knowledge, a novel one that captures the true essence of the problem while also revealing its relationship to the holdup problem. Section 5 then discusses the fundamental commonality between the two problems, as well as the nature of their differences.

\section{Examples of the Holdup and Holdout Problems}

The holdup problem is well illustrated by the case of Goebel v. Linn. ${ }^{3}$ The defendant in that case was a brewer who had contracted with an ice company to supply ice during the summer months to ensure that his beer did not spoil. The contract called for the delivery of ice according

\footnotetext{
${ }^{3} 11$ N.W. 284 (1882). Also see the economic analysis of this case in Posner (1977) and Miceli (2002).
} 
to a pre-set price schedule, but because of an unusually warm winter, the market price of ice had risen well above the contract price, so the ice company refused to make delivery at that price. Fearing loss of his stock of beer, the brewer therefore agreed to a price increase, and the contract was completed. Later, however, the brewer regretted his decision and reneged on paying the higher price, but the court upheld the price increase on the grounds that economic circumstances had changed in an unexpected way and the increase was needed to ensure the economic viability of the ice company. The point for our purposes is that the brewer's need to invest in the production of beer before the cost of ice was known left it vulnerable to being held up by the ice company later on. ${ }^{4}$ Had the brewer anticipated the higher price he would have to pay for ice, he would presumably have scaled back his beer production.

The holdout problem was at the center of the recent and controversial Supreme Court case of Kelo v. City of New London, ${ }^{5}$ which allowed the use of eminent domain for a large scale redevelopment project aimed at revitalizing the downtown area of the city. Although the development authority initially attempted to acquire the necessary land through market purchases, a small group of owners refused to sell, and so the city sought to use the power of eminent domain to forcedly acquire their land. The Supreme Court granted the city's request, arguing that although the primary beneficiaries of the project were private entities, the overall redevelopment plan promised sufficient spillover benefits to the public in terms of jobs and enhanced tax revenues that it met the public use requirement of the Fifth Amendment. ${ }^{6}$ Despite the controversy over the case, the facts present a classic holdout problem, whereby a few owners acquire substantial bargaining power vis-à-vis the buyer by virtue of their ability to stop the

\footnotetext{
${ }^{4}$ Because it had a contract, the brewer could have sought damages for breach when the ice company refused to honor the contract price, but it chose not to do so. In this sense, the case illustrates the difficulty of writing enforceable contracts in such settings.

5 545 U.S. 469 (2005).

${ }^{6}$ As it happened, however, the project never materialized. See Benedict (2009) for an interesting history of the case.
} 
project through their refusal to sell. A developer who anticipates this is less likely to go forward with the project in the first place.

The final case we discuss, Boomer v. Atlantic Cement Co. ${ }^{7}$ is interesting because it embodies both problems. The case involved a nuisance suit brought by several residents living near a cement plant operated by the defendants. The plaintiffs sought to have the plant shut down due to the noise and dust that it caused, but the court rejected the request for an injunction and instead ordered the plant to pay damages, thereby allowing it to continue operating. The court's reasoning was based on the loss of over $\$ 45$ million in assets and 300 jobs if the plant had been forced to shut down, compared to the estimated damages of $\$ 185,000$ that its continued operation would have imposed on the plaintiffs. Thus, allowing the plant to continue to operate was the efficient decision.

Goldberg's (1985) analysis of the Boomer decision casts it as a holdup problem based on the argument that, once the plant was in place, granting the nearby residents the right to shut it down would have given them substantial bargaining power in any negotiations with the plant over its right to pollute. Thus, while the granting of an injunction may not have resulted in the plant's actual closing given its high value relative to the external costs it imposed, it would likely have chilled future entrepreneurs from making similar investments, suggesting that from a social perspective too few plants would be built. Goldberg thus argues that the damage remedy was appropriate because it did not allow the residents to hold up the plant ex post.

Fischel (1995, pp. 75-77) reaches the same conclusion regarding the Boomer casenamely that a damage remedy was appropriate—but justifies the ruling instead as overcoming a holdout problem. ${ }^{8}$ As he sees it, the problem with an injunction is that it would have required the

\footnotetext{
7309 N.Y.S.2d 312 (1970).

${ }^{8}$ Also see the discussion of the case in Cooter and Ulen (1988, pp. 175-176), on which Fischel's argument is based.
} 
cement company to negotiate with multiple residents because of the necessity to convince each of them to forego enforcing the injunction. In other words, the company would have had to "assemble" pollution rights from the residents, any one of whom could have prevented the plant from operating. The court's issuing of a damage remedy thus effectively allowed the cement company to "take" the pollution rights in return for compensation. 9

The Boomer case exemplifies the commonality between the holdup and holdout problems by revealing that they stem from the same source-namely, the need for one party to a potential transaction to pre-commit to the transaction in a way that confers bargaining power on another party or parties. The models in the next two sections illustrate that point more formally.

\section{The Holdup Problem}

Consider a party that undertakes an activity or project (e.g., the production and sale of beer), the completion of which requires the purchase of an input (e.g., ice) at a later date. Suppose that the first party (the buyer) enters into a contract with a second party (the seller) that calls for the seller to produce the input and deliver it to the buyer at some future date (assuming a mutually beneficial transaction can be negotiated at that time). At the time the contract is made, the seller's cost of producing the input, $C$, is uncertain, though both the buyer and seller know its cumulative distribution function, $F(C)$, where $F^{\prime} \equiv f>0$. At some point prior to the delivery date, however, the actual cost is realized and observed by both parties.

We assume, as is typical in the literature on hold-ups, that the contract cannot be made contingent on the realized cost, and that the parties cannot pre-commit to a price. This means that the transaction price is effectively determined by a spot contract after $C$ is realized. It

\footnotetext{
${ }^{9}$ This reflects the fact that damages and eminent domain are both "liability rules." See Calabresi and Melamed (1972).
} 
follows that whenever there is a gain from trade, the parties will transact (assuming zero bargaining costs), and that the price will be determined by ex post bargaining.

The gross value of the completed project to the buyer is known at the time of contracting and depends on a non-salvageable, transaction-specific investment that enhances the value of performance. (For example, the more beer the buyer brews, the higher will be his possible net revenue from beer sales.) Let $V(x)$ be the buyer's valuation of the project exclusive of any payment made to the seller, where $x$ is the dollar investment, and $V^{\prime}>0, V^{\prime \prime}<0 . \quad$ If the contract is mutually beneficial ex post, i.e., if $V(x) \geq C$, then the parties will negotiate the price and conclude the sale, allowing the buyer to complete the project. Conversely, if $V(x)<C$, the sale will not be completed, and the buyer will not go forward with the project. As a result, he will lose his initial investment $x$. The timing of events is crucial: first, the buyer invests $x$, then the seller's cost of production is realized (which determines whether the parties will go ahead with the contracted sale), and, finally, conditional on proceeding with the sale, the parties negotiate the price.

The social optimum is found by backwards induction. Once the cost of production is realized, it is efficient for the sale to take place and the project to be completed if and only if $V(x) \geq C$ for any prior choice of $x .^{10}$ Now move back to the point where $x$ is chosen. Given the condition for an efficient sale, the expected joint surplus from the contract is equal to

$$
F(V(x)) E[V(x)-C \mid V(x) \geq C]-x=\int_{0}^{V(x)}[V(x)-C] f(C) d C-x
$$

The optimal choice of $x$ maximizes this expression. Assuming an interior solution, the first order condition defining $x *$ is given by

$$
F(V(x)) V^{\prime}(x)-1=0,
$$

\footnotetext{
${ }^{10}$ We assume that when indifferent, the parties transact.
} 
which says that the expected marginal value of investing should be set equal to the marginal cost. $^{11}$

Now consider the actual decisions of the parties. For any prior choice of $x$ by the buyer, the parties will transact if and only if a mutually beneficial trade exists, i.e., if and only if $V(x) \geq C$, which is the ex post efficient condition. Assuming Nash bargaining with equal bargaining strengths, ${ }^{12}$ the resulting price will be

$$
P=\frac{V(x)+C}{2}
$$

Given the buyer's rational expectation of the price, he will choose $x$ to maximize his expected surplus, which is given by

$$
F(V(x)) E[V(x)-P \mid V(x) \geq C]-x=\int_{0}^{V(x)}[V(x)-P] f(C) d C-x
$$

Substituting for $P$ from (3) and setting the derivative of (4) with respect to $x$ equal to zero yields the first order condition for the buyer's privately optimal investment (again assuming an interior solution):

$$
\frac{F(V(x)) V^{\prime}(x)}{2}-1=0
$$

Comparing this condition to (2) shows that the buyer under-invests relative to the social optimum. This represents the inefficiency associated with the holdup problem.

For purposes of thinking about how the preceding analysis relates to the holdout problem, it is worth examining more carefully the specific source of this inefficiency. Although the existence of cost uncertainty on the part of the seller reflects the facts of the Goebel case, and is usually included in standard models of holdups, this is not an essential feature of the holdup

\footnotetext{
${ }^{11}$ We assume that the second order condition, $F V^{\prime \prime}+F^{\prime} V^{2}<0$, is satisfied.

12 The assumption of equal bargaining strengths is not essential.
} 
problem. The conclusions above would be unchanged if $F(V(x)) \equiv 1$. What is crucial is the transaction-specific nature of the buyer's initial investment (the choice of $x$ ), which, because it is sunk, commits him to the transaction in a way that the seller can exploit at the time the parties negotiate the price. The following simplified model, which reflects the facts of the Boomer case, highlights this aspect of the problem and thus provides a more transparent basis of comparison with the holdout model below.

Let $V$ be the gross value of the project, which can only be realized if the buyer first makes a fixed up-front investment, $x$, that is non-salvageable, and then purchases an input whose known cost is $C$. In the Boomer case, $x$ represents the initial investment in the cement plant, $C$ is the external harm the plant's operation imposes on nearby residents (the essential input), and $V$ is the gross profit from operation of the plant. We assume that the value of the plant exceeds the social costs so that operation of the plant is socially optimal; that is,

$$
V>C+x
$$

To see the impact of the holdup problem on private decisions, suppose that after $x$ has been spent, the plant owner must purchase the right to impose the external harm on the residents before it can legally operate. (This would have been true, for example, if the court in Boomer had granted the plaintiffs' request for an injunction.) This sequence of events is the crucial feature of the holdup problem. Once $x$ has been spent, the determination of the price proceeds as in the above model. The net gain to the plant owner from purchasing the right to operate from residents (acting collectively) is $V-P$, while the net gain to the resident(s) is $P-C$. The resulting price, which splits the surplus, is therefore

$$
P=\frac{V+C}{2}
$$


which is the analog to (3). As for the decision to invest $x$, the plant owner will find it profitable to do so if and only if he expects to earn a profit, or if and only if $V-P-x \geq 0$. After substituting from (7) this condition becomes

$$
V \geq C+2 x
$$

Depending on the parameter values, it is possible that (6) holds but (8) does not. It follows that some plants that are efficient will not be built because of the holdup problem.

[Figure 1 here]

The inefficiency from the holdup problem is shown graphically in Figure 1, where the downward sloping line reflects the value of all possible plants, the horizontal line labeled $C+x$ is the social cost per plant, and the line labeled $C+2 x$ is the actual cost to plant owners. The actual number of plants, $n_{a}$, is therefore less than the efficient number, $n^{*}$.

To verify that the inefficiency stems from the need to bargain after the investment in $x$ has been made, note that with ex ante bargaining, the price of the input is set at

$$
P=\frac{(V-x)+C}{2}
$$

With this price, the buyer proceeds with the project if and only if $V-P-x$, or

$$
\frac{V-x-C}{2} \geq 0
$$

which holds if and only if the project is efficient.

\section{The Holdout Problem}

The prototypical holdout problem arises when a buyer wishes to assemble a number of contiguous, independently owned parcels of land with the intention of undertaking a large 
investment project like a highway or a shopping center. ${ }^{13}$ The crucial aspects of the problem are, first, that there is a complementarity among the parcels to be assembled, which makes them collectively more valuable to the buyer than to the individual sellers; and second, that the buyer values individual parcels less than their current owners. The first point implies that assembly is socially productive, while the second imposes a kind of all-or-nothing element to the proposed project (or at least implies that partial assembly is not socially desirable).

To capture this formally, we consider a simple case where a buyer wishes to acquire two contiguous but individually-owned parcels of land. (The analysis easily generalizes to $n>2$.) Let $V$ represent the gross value of the assembled parcels, and let $R$ represent the reservation price of each owner, ${ }^{14}$ where we assume that

$$
V>2 R
$$

This condition reflects the complementarity. We also assume that the value of any one parcel alone to the buyer is $v \geq 0$, where

$$
v<R
$$

This condition reflects the inefficiency of "partial" assembly. ${ }^{15}$

Now consider the actual process by which the buyer attempts to acquire the parcels. If sellers are ignorant of the buyer's ultimate plan, his purchases should proceed smoothly, with no impediment to the completion of individual sales (absent bargaining costs). In other words, individual transactions should be independent of one another in this case. Sometimes, the assumption of independent purchases will be a reasonable one, especially for private

\footnotetext{
${ }^{13}$ For purposes of this discussion, we will not distinguish between public and private projects, as the nature of the holdout problem is independent of the type of project.

${ }^{14}$ It is not essential that the reservation prices of the owners be identical.

${ }^{15}$ The value $v$ represents the how much the property is worth to the buyer in terms of use. One might argue that if the assembly project falls through, the buyer would seek to re-sell the property, perhaps back to the original owner, for a price that would be higher than $v$. Such a transaction, however, would likely result in a price less than $R$ given that the buyer's reservation price at this point is $v<R$.
} 
development projects where the developer may be able to use secret buying agents to disguise his ultimate purpose. However, this is rarely possible for public projects (like highways), or publicly sponsored private projects (like urban redevelopment), since the need for public financing will require the nature of the project to be revealed before assembly can commence. And even for purely private projects, at some point the buyer's intent will become clear. In that case, sequential bargaining between the buyer and sellers will likely unfold differently.

As in the case of the holdup problem, we work in reverse sequence of time. Thus, suppose that the buyer has already acquired the first parcel for a price of $P_{1}$. He thus proceeds to negotiate with the second buyer. Since the purchase of parcel one is a sunk investment for the buyer, his threat point in negotiating for the second parcel is $v$, his valuation of a single parcel. If he acquires the second parcel for a price $P_{2}$, his net gain is therefore $V-v-P_{2}$, while the seller's net gain is $P_{2}-R$. The resulting price will be

$$
P_{2}=\frac{V-v+R}{2}
$$

which divides the joint surplus from the transaction, $V-v-R$, evenly.

Now move back to the negotiations between the buyer and the first seller. Because the seller is assumed to be aware of the buyer's desire to assemble the two parcels, the two parties correctly anticipate the subsequent bargaining over the second parcel. Given that, the buyer's surplus from acquiring the first parcel is $V-P_{1}-P_{2}$, while the seller's surplus is $P_{1}-R$. The resulting price, which equally shares the expected surplus of $V-R-P_{2}$, is given by

$$
P_{1}=\frac{V+R-P_{2}}{2}
$$

Substituting for $P_{2}$ from (13) and rearranging yields

$$
P_{1}=\frac{V+v+R}{4}
$$


Comparing (13) and (15), we find that

$$
P_{2}-P_{1}=\frac{V-3 v+R}{4}
$$

which is positive if and only if

$$
V+R>3 v .
$$

Since this condition must hold given the assumptions in (11) and (12), we conclude that $P_{2}>P_{1} \cdot{ }^{16}$ This re-enforces the conventional wisdom that in assembly problems, if sellers are able to choose when to bargain with the buyer, they are better off waiting because they are thereby able to extract a larger share of the buyer's surplus. In other words, "holding out" is a profitable strategy. ${ }^{17}$ Moreover, notice that the differential between $P_{2}$ and $P_{1}$ is decreasing in $v$, all else equal. Thus, as the buyer's valuation of a single parcel decreases, the second seller is able to extract a larger share of the surplus from the overall project.

Finally, note that given (16), $P_{1}>v$, which implies that the buyer pays more for parcel 1 than it is worth to him as an individual parcel. It is in this sense that the holdout problem resembles the holdup problem. Note in particular that the purchase of the first parcel here is analogous to the buyer's transaction specific investment of $x$ above because both are sunk investments that lock the buyer into the transaction, thereby conferring bargaining power on the later seller. In the holdup context, we showed that because the buyer anticipates this opportunistic behavior by the seller, the buyer under-invests in the transaction relative to the socially optimal outcome. A similar inefficiency arises in the holdout context in the form of too few projects involving assembly being undertaken.

\footnotetext{
${ }^{16}$ This result is obviously contingent on the assumption that the two sellers have equal reservation prices. Thus, the result that the second seller extracts a higher price is an all-else-equal conclusion.

${ }^{17}$ See Miceli and Segerson (2007), who explicitly model the decision of sellers regarding when to bargain with the buyer.
} 
To demonstrate this result, note that a buyer will only initiate a project if he expects to earn a profit, or if and only if $V-P_{1}-P_{2} \geq 0$. Using (13) and (15), we find that this condition will hold if and only if

$$
V \geq 2 R+(R-v)
$$

which may or may not be true given (11) and (12). Thus, even though a project is efficient by (11), the buyer may not initiate it because of the inefficiency associated with the holdout problem. This is shown graphically in Figure 2, where the downward sloping line shows the value of all possible assembly projects. As was true with the holdup problem in Figure 1, the actual number undertaken, $n_{\mathrm{a}}$, is less than the efficient number, $n^{*}$, whenever $R>v$.

[Figure 2 here]

\section{Discussion}

The preceding analysis highlights the relationship between the holdup and holdout problems. The fundamental similarity, which to our knowledge has not been recognized in the literature, is that both problems arise in the context of a project undertaken by one party (the buyer) that has the following characteristics:

(1) it involves an up-front, non-salvageable commitment of resources;

(2) it relies on the purchase of a good or service from another party or parties in order for the project to be completed;

(3) the price of that good or service is determined by bargaining; and

(4) the bargaining takes place after the initial commitment of resources by the buyer. The effect of the up-front, non-salvageable commitment by the buyer is to reduce his bargaining power with the seller of the input necessary for completion of the project, the anticipation of 
which effect creates a disincentive for the buyer to undertake the project in the first place. As a result, some projects or activities that are socially efficient are foregone.

While we argue that the holdup and holdout problems involve the same fundamental economic problem, clearly the contexts they represent differ. The holdup problem is typically couched in terms of only two parties (a buyer and a seller) where incomplete contracting (due to uncertainty or non-verifiability) forces bargaining to occur after the initial investment is made by the buyer. In contrast, the holdout problem arises in assembly contexts, which by definition must involve at least three parties (one buyer and at least two sellers). In this context, it is the need to bargain sequentially with the two (or more) sellers that forces the bargaining with the second seller to occur after the initial commitment is made by the buyer. Here, the commitment is the purchase of land from the first seller. This represents an unrecoverable investment since, as noted above, the buyer pays more for the first parcel than it is worth to him as an individual parcel, implying that he will lose his investment of $P_{1}-v>0$ if the project is not completed.

To highlight these differences, we turn again to the Boomer case, which, as noted above, involves both problems. Since under an injunction bargaining between the plant owner and the neighboring residents would have been conducted after the investment in the plant was made, this feature of the case represents a holdup problem, which would occur even if there were only one resident who would be a party to the bargaining. Possible "solutions" to this aspect of the problem would have been for the firm and resident(s) to negotiate a sale of operating rights, or easements, prior to the investment in the plant, as suggested by Goldberg (1985), or, in the context of the Goebel case, for the firm and the input supplier to vertically integrate.

In addition, though, the Boomer case involved multiple residents. The need to bargain with them sequentially is what gives rise to the holdout problem. Note that this problem would 
exist even if contracting over operating rights and compensation occurred prior to the investment in the factory. Possible "solutions" to this problem involve collective bargaining (to eliminate the need for sequential bargaining), or the use of a liability rule (i.e., a forced sale), which is what the court actually allowed in the Boomer case. Thus, while we argue that the holdup and holdout problems stem from the same underlying economic problem, the different contexts in which they arise imply quite different prescriptions for eliminating the resulting inefficiency. 


\section{References}

Benedict, J. (2009) Little Pink House: A True Story of Defiance and Courage. New York: Grand Central Publishing.

Bolton, P. and M. Dewatripont (2005) Contract Theory, Cambridge, MA: MIT Press,

Calabresi, G. and A. D. Melamed (1972) "Property Rules, Liability Rules, and Inalienability: One View of the Cathedral," Harvard Law Review 85: 1089-1128.

Cooter, R. (2000) The Strategic Constitution, Princeton: Princeton Univ. Press.

Cooter,R. and T. Ulen (1988) Law and Economics, Glenview, IL: Scott Foresman and Co.

Edlin, A. and S. Reichelstein (1996) "Holdups, Standard Breach Remedies, and Optimal Investment," American Economics Review 86: 478-501.

Fischel, W. (1995) Regulatory Takings: Law, Economics, and Politics, Cambridge, MA: Harvard Univ. Press.

Goldberg, V. (1976) "Regulation and Administered Contracts," Bell Journal of Economics 7: 426-448.

(1985) "Relational Exchange, Contract Law, and the Boomer Problem," Journal of Institutional Economics 144: 100-116.

Hart, O. and J. Moore (1988) "Incomplete Contracts and Renegotiation,” Econometrica 56: 755 785.

Heller, M. (1999) “The Boundaries of Private Property,” Yale Law Journal 108: 1163-1223.

Klein, B., R. Crawford, and A. Alchian (1978) "Vertical Integration, Appropriable Rents, and the Competitive Contracting Process," Journal of Law and Economics 21: 297-326.

Menezes, F. and R. Pitchford (2004) “A Model of Seller Holdout,” Economic Theory 24: 231253.

Miceli, T. (2002) “'Over a Barrel': Contract Modification, Reliance, and Bankruptcy," International Review of Law and Economics 22: 41-51.

Miceli, T. and K. Segerson (2007) “A Bargaining Model of Holdouts and Takings," American Law and Economics Review 9: 160-174.

Posner, R. (2003) Economic Analysis of Law, $6^{\text {th }}$ Edition. New York: Aspen Law \& Business. 
_(1977) Gratuitous Promises in Economics and Law," Journal of Legal Studies 6: 411426.

Segal, I. (1999) "Complexity and Renegotiation: A Foundation for Incomplete Contracts," Review of Economic Studies 66: 57-82.

Strange, W. (1995) "Information, Holdouts, and Land Assembly," Journal of Urban Economics 38: $317-332$. 


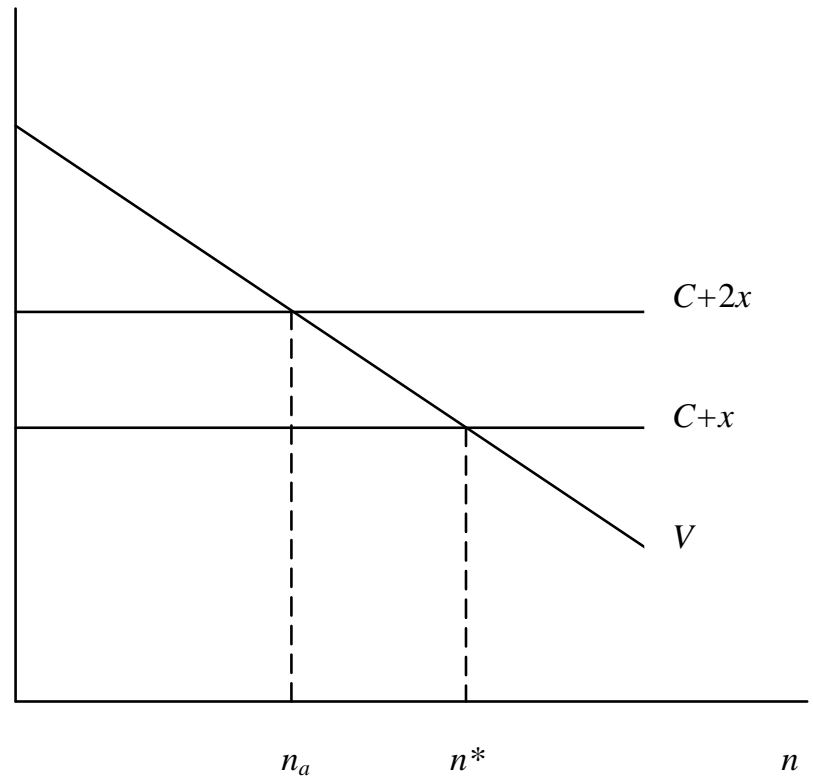

Figure 1. In efficiency associated with the holdup problem. 


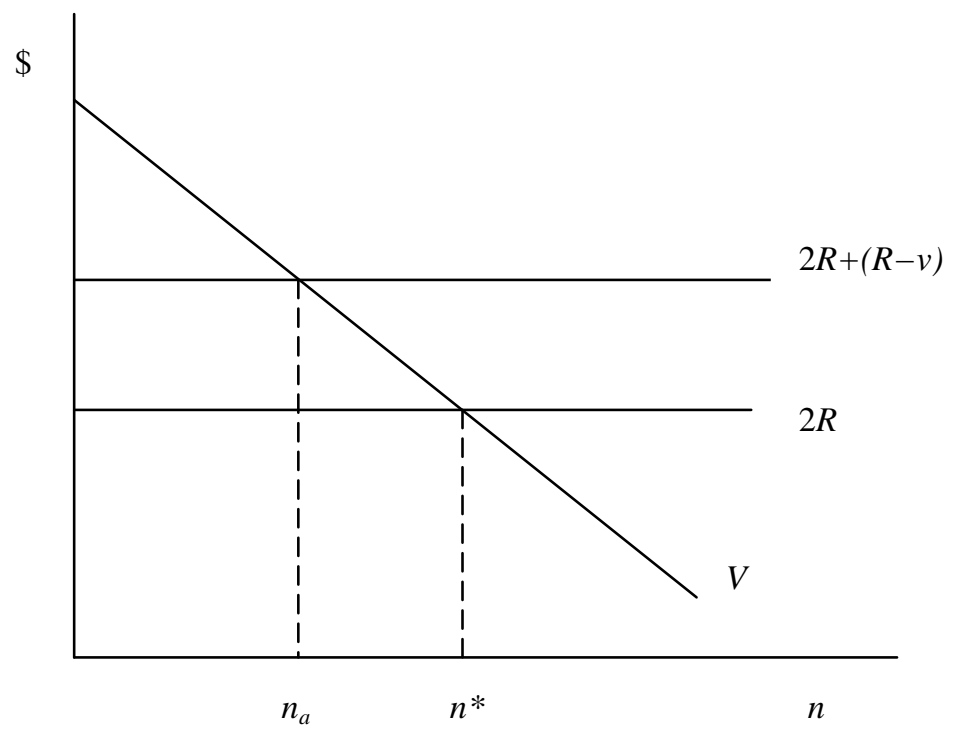

Figure 1. Inefficiency associated with the holdout problem. 